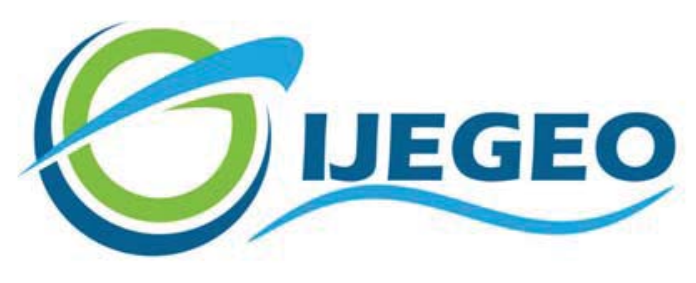

International Journal of Environment and Geoinformatics (IJEGEO) is an international, multidisciplinary, peer reviewed, open access journal.

\title{
Crop Phenology-Based Object-Oriented Classification Approach Using SENTINEL-2A and NDVI Time Series: Sunflower Crops in Kirklareli TURKEY
}

\section{Armağan ALOE KARABULUT, Nihal CEYLAN, Erdem BAHAR, İlker KURŞUN}

\author{
Chief in Editor \\ Prof. Dr. Cem Gazioğlu \\ Co-Editors \\ Prof. Dr. Dursun Zafer Şeker, Prof. Dr. Şinasi Kaya, \\ Prof. Dr. Ayşegül Tanık and Assist. Prof. Dr. Volkan Demir
}

Editorial Committee (September 2021)

Assoc. Prof. Dr. Abdullah Aksu (TR), Assit. Prof. Dr. Uğur Algancı (TR), Prof. Dr. Bedri Alpar (TR), Assoc. Prof. Dr. Aslı Aslan (US), Prof. Dr. Levent Bat (TR), Prof. Dr. Paul Bates (UK), İrşad Bayırhan (TR), Prof. Dr. Bülent Bayram (TR), Prof. Dr. Luis M. Botana (ES), Prof. Dr. Nuray Çağlar (TR), Prof. Dr. Sukanta Dash (IN), Dr. Soofia T. Elias (UK), Prof. Dr. A. Evren Erginal (TR), Assoc. Prof. Dr. Cüneyt Erenoğlu (TR), Dr. Dieter Fritsch (DE), Prof. Dr. Çiğdem Göksel (TR), Prof.Dr. Lena Halounova (CZ), Prof. Dr. Manik Kalubarme (IN), Dr. Hakan Kaya (TR), Assist. Prof. Dr. Serkan Kükrer (TR), Assoc. Prof. Dr. Maged Marghany (MY), Prof. Dr. Michael Meadows (ZA), Prof. Dr. Nebiye Musaoğlu (TR), Prof. Dr. Masafumi Nakagawa (JP), Prof. Dr. Hasan Özdemir (TR), Prof. Dr. Chryssy Potsiou (GR), Prof. Dr. Erol Sarı (TR), Prof. Dr. Maria Paradiso (IT), Prof. Dr. Petros Patias (GR), Prof. Dr. Elif Sertel (TR), Prof. Dr. Nüket Sivri (TR), Prof. Dr. Füsun Balık Şanlı (TR), Prof. Dr. Uğur Şanlı (TR), Duygu Ülker (TR), Prof. Dr. Seyfettin Taş (TR), Assoc. Prof. Dr. Ömer Suat Taşkın (TR), Assist. Prof. Dr. Tuba Ünsal (TR), Dr. Manousos Valyrakis (UK), Dr. İnese Varna (LV), Dr. Petra Visser (NL), Prof. Dr. Selma Ünlü (TR), Assoc. Prof. Dr. Oral Yağcı (TR), Prof. Dr. Murat Yakar (TR), Assoc. Prof. Dr. İ. Noyan Y1lmaz (AU); Assit. Prof. Dr. Sibel Zeki (TR) 


\title{
Crop Phenology-Based Object-Oriented Classification Approach Using SENTINEL- 2A and NDVI Time Series: Sunflower Crops in Kurklareli TURKEY
}

\author{
Armağan Aloe Karabulut ${ }^{1 \text {,* (D) , Nihal Ceylan }}{ }^{1}$ (D) Erdem Bahar ${ }^{2}$ (iD , ilker Kurşun² ${ }^{\text {iD }}$ \\ ${ }^{1}$ Central Research Institute for Field Crops, Ankara, TURKEY \\ ${ }^{2}$ Atatürk Soil, Water, and Agricultural Meteorology Research Institute, Kırklareli, TURKEY \\ * Corresponding author: A. A. Karabulut \\ Received 11 Jan. 2021 \\ E-mail: armagankarabulut@tarimorman.gov.tr \\ Accepted 26 Feb. 2021 \\ How to cite: Karabulut, et al., (2021). Crop phenology-based object-oriented classification approach using SENTINEL-2A and NDVI time \\ series: Sunflower crops in Kirklareli. International Journal of Environment and Geoinformatics (IJEGEO), 8(3): 316-327. doi. 10.30897/ \\ ijegeo. 858456
}

\begin{abstract}
Achieving food security on a global scale depends on regular spatio-temporal monitoring and management of national and local agricultural production. The aim of this study is to develop a methodology for determining sunflower cultivated areas using high resolution time series of the SENTINEL-2A satellite images that represent phenological stages of crop growth cycle. A time series of spectral signatures of crop phenological periods and normalized difference vegetation index (NDVI) was produced from satellite images for year 2018. A stepwise object-oriented classification approach was developed. In this approach, object-oriented segmentation and classification decision tree algorithms were produced by using time series of spectral signatures and NDVI values as well as object shape criteria and other auxiliary thematic maps. The multiresolution method of "Canny edge" algorithm was used in order to determine boundary of agricultural parcels. The best performance in segmentation to determine the agricultural parcels was achieved by increasing weight coefficient of the "Canny edge" layer. Object-oriented classification was carried out based on these segmented parcels. First, summer crops, winter crops, fallow and permanent vegetated areas were determined through classification decision tree algorithms. Later, the summer and winter crops were classified using the parcel spectral signatures of samples collected with field work. The crops whose class definition could not be determined were passed through a second elimination in "unclassified" group and later assigned to their classes. Finally, the parcels whose class definition could not be determined were grouped as "other" class. According to results of confusion matrix and accuracy analysis, sunflower, which was determined in two classes as early and late sowing, was classified at $98 \%$ and $92 \%$ accuracy, respectively.
\end{abstract}

Keywords: Object-oriented Classification, NDVI Time Series, Sunflower, Crop Phenology, SENTINEL-2A, Decision Tree

\section{Introduction}

Within the framework of sustainable development goals, global food security requires meeting food needs of everincreasing population, increasing food diversity and ensuring people access to food (GA, 2015). Food security of nations requires an increment in agricultural production capacity by optimizing the soil-water resources with appropriate land use and crop pattern planning. In this context, determining the cultivation areas of crops and spatio-temporal monitoring in crop production planning is very important to ensure decision makers have more precise crop yield estimates in their hands on time (Alganci et al.2014).

Updated data of annual crop pattern and rotation is essential for spatio-temporal management of crop production. In Turkey, such spatial data are provided by the "Farmer Registration System" (TOB-ÇKS) (2020) and the "Agricultural Parcels Information System" (APIS, 2020). However, as the information of crop type and yield of parcels is based on farmer declaration that is registered in the system, accuracy of data cannot be controlled for each parcel. Furthermore, there is a high probability that there are farmers who are not registered in the system yet. Therefore, annual crop pattern and rotation data need to be provided and updated by a dynamic monitoring and control methods. Spatiotemporal analysis of satellite images at different wavelengths is an operational technological opportunity that enables examining dynamic structure of crop pattern and rotation.

Determination of agricultural areas and classification of crop patterns using remote sensing and GIS techniques, further development of crop monitoring techniques started with pixel-based approaches (Sabins, 1987; Drury, 1990; Evsahibioglu, 1994; Esetlili and Kurucu, 2003; Balcik and Kuzucu, 2016; Esetlili, et al., 2018), and later with the improvement of radiometric, spatial and temporal high-resolution images and high speed processing techniques, pixel-based classification techniques gave way to object-oriented classification methods where artificial intelligence, machine and deep learning methods are frequently used (Rahman and Saha, 2008; Irfanoglu and Balcik, 2018; Bargiel, 2017; Cicek and Founder, 2018; Colkesen and Kavzanoglu, 2017; Ghamisi et al.2017; Maxwell et al.2018). Even though studies on these issues at national scale are carried out within the body of different institutions affiliated to the 
Ministry of Agriculture and Forestry in Turkey, they remain insufficient without mutual communication. Depending on feasibility of current situation, interoperability between institutions should also be ensured.

Sunflower, one of the most important oil-seed crops in the world, has a high production potential in Turkey as well. In Turkey, half of the oil-seed production is met from sunflower (ESKGM, 2019). Trakya region meets an important part of oil-seed sunflower and paddy production for the country as well as wheat is produced in the region with a yield above the country's average. As a result, $60-65 \%$ of sunflower and $10-15 \%$ of cereal production in dry conditions are produced in the Trakya region. While annual sunflower oil consumption in Turkey is 900 thousand tons/year, oil-seed sunflower production can only meet half of this need, and the remaining half is provided by imports (ESKGM, 2019). Despite its production potential of oil-seed sunflower, Turkey takes the second place after the European Union in importing oil-seed sunflower (TOBB, 2018). Therefore, more effective crop production plans need to be developed with support of highly accurate annual yield estimates in order to meet the sunflower needs in Turkey with domestic production as well as appropriately subsiding farmers/producers. Highly accurate annual yield estimation primarily depends on the determination of accurate annual crop pattern.

In this context Kırklareli, which has an important role in agricultural economy in Turkey, was selected as the study area for determining sunflower cultivated areas. We aimed to develop a methodology for determining the sunflower cultivated areas using high resolution time series of the SENTINEL-2A satellite images that represent phenological stages of the crop growth cycle. First, we generated a spectral signature database for growth cycle periods of main crops using time series of SENTINEL-2A satellite images and NDVI values. Then we developed a stepwise object-oriented classification method based on this spectral signature database as well as auxiliary GIS data and narrative-based knowledge. Finally, we determined the sunflower cultivated areas with a high accuracy and main crop pattern as well.

\section{Study area}

Kirklareli has an area of $6550 \mathrm{~km}^{2}$ between the Istranca Mountains and Ergene plain in Thrace, and its average altitude above sea level is $203 \mathrm{~m}$. The highest region is $1018 \mathrm{~m}$ in Mahya Mountain (Kuru and Terzi, 2018). Its north and east parts are covered by forests while other parts are surrounded by fertile agricultural plain land (Figure 1). The winters in the region are dominated by harsh and rainy continental climate conditions as well as cold weather coming from the Balkans while summers are hot with semi-arid climatic characteristics. Although inner regions of Kirklareli receive rainfall almost in every season, annual precipitation is low compared to coastal regions (Erginal and Uludağ, 2018). In these regions, the average temperature is $13{ }^{\circ} \mathrm{C}$ and the mean annual precipitation is $772.8 \mathrm{~mm}$ (MGM, 2018). According to the Köppen Climate classification, Kirklareli Province is in the "Mediterranean / humid semi-tropical climate characteristics (border region)" class. The main rivers are Ergene River and Mutlu Creek where irrigated agriculture is practiced surround (Figure $1)$.

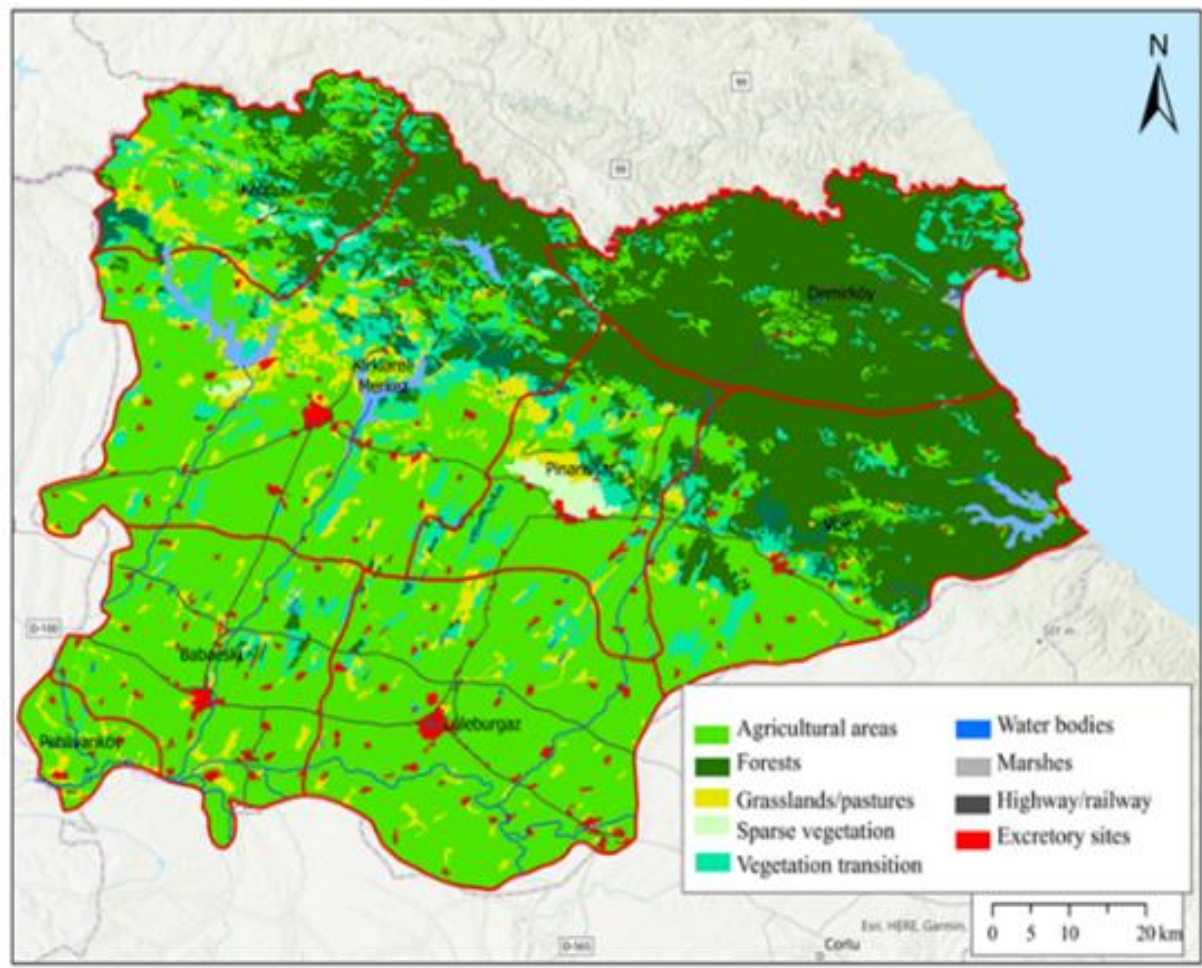

Figure 1. Study area and land use (CORINE CLC 2018). 
According to the land use distribution of Kirklareli (CORINE-18 CLC) (Figure 1), total agricultural land is 264.532 hectares (ha) and size of the agricultural parcels varies between 5-20 ha. Cereals are among the most cultivated crops in Kirklareli, and sunflower production meets $10 \%$ of the country in general (TOB, 2018). While TOB-ÇKS data reports a sunflower cultivated area of 66.909 ha, Turkey's Statistical Institution (TÜIKK)'s data reports instead a total area of 75.000 ha for year 2018 .

\section{General crop production status}

Kirklareli has a population of 351.684 , and $70 \%$ of the active population is engaged in agriculture, animal husbandry, forestry and hunting (TOBB, 2018). Major agricultural products are cereals, sunflower, maize, grain legumes, sugar beet, canola, alfalfa and vetch (Çaldağ, 2009). Main winter crops cultivated in the region are grains, canola and vetch on the non-irrigated dry lands, while summer crops are sunflower, sugar beet, maize, alfalfa and vetch on the irrigated lands. Sunflower is grown at different sowing times depending on the rainfall regime on the non-irrigated areas.

Second crop cultivation on the irrigated lands has also increased in the last decade in the region. Silage maize, dry beans and second crop sunflower are planted as second crop after the harvest of cereals and winter canola. Different crop alternation models can be applied in the region as given below (TOBB, 2018):

Model 1: sunflower + canola + wheat + maize

Model 2: wheat + canola + legumes + sunflower
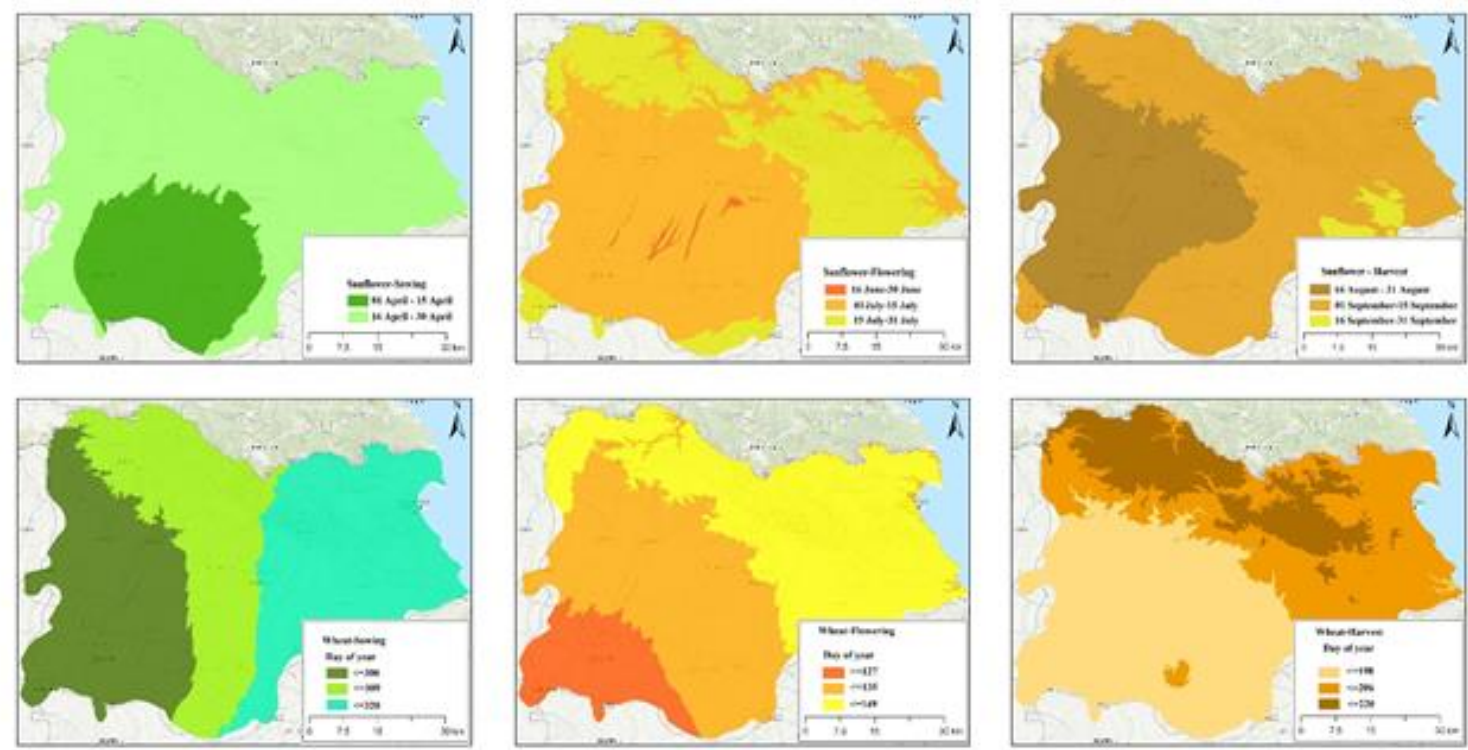

Figure 2. Atlas of sunflower and wheat phenological periods in Kurklareli (a-f) (MGM, 2014).

In this study, crop phenology atlases (MGM, 2014), expert and literature based knowledge were used to determine the phenological periods for the main crops. A phenology calendar matrix (see Figure 3) was created for the strategic main crops using the crop phenology atlases (see Figure 2) which were produced based on long-term phenological observation data (MGM, 2014). Ideally, phenological observations should be performed in
Model 3: wheat + canola + sugar beet + melonwatermelon

\section{Materials and Methods}

\section{SENTINEL-2A satellite imagery time series}

The SENTINEL-2A satellite images of year 2018 were scanned in the Copernicus database (EU-Copernicus, achieved at:20/05/2019), and the most suitable cloudless images were downloaded.

Kirklareli is located at a intersection of four image frames. For this reason, in a window of a certain time, an image existing in one frame may not exist in other frame. Those windows with cloudless complete frames that represent the phenological periods (see Figure 3) were pre-examined and prepared ready as a time series of multispectral satellite images for image processing and classification processes. ArcGIS, e-Cognition and Erdas programs were used interactively for all processes.

\section{Crop phenology calendar matrix}

While main purpose of this study is to determine the sunflower cultivation areas, in order to distinguish sunflower from other main crops, additional information about other crops should also be determined and used as an auxiliary criteria in classification algorithms. For instance, since phenological periods for main crops could not be monitored in the field, auxiliary algorithm criteria were determined based on the available data (Figure 2) 
late sunflower sowing periods whose phenological stages coincide with different times in the region. In addition, silage maize is produced as a second crop. For this reason, it is essential determining the phenological periods (Figure 3 ) between sowing and harvest periods for the main crops in the region in order to distinguish better. Generally sowing dates may vary depending on the morphological structure in the region. While early sowing is made especially in the south flat plains, a little later sowing may be in question in the north higher areas and, therefore, different phenological growth timing can be observed for same crop (Figure 2). As a result of the literature study carried out, sunflower is generally sown during the first week of April depending on the climate conditions, and crop emergence occurs at the end of April in Kurklareli. Foliation and flower table are formed by the end of the first week of May. Flowering begins in mid-June. By entering the ripening phase, it starts to dry in mid-July. It is determined that sunflower is harvested after the second week of August (Bakanoğulları, 2018; Göneci, 2019) (Figure 3).

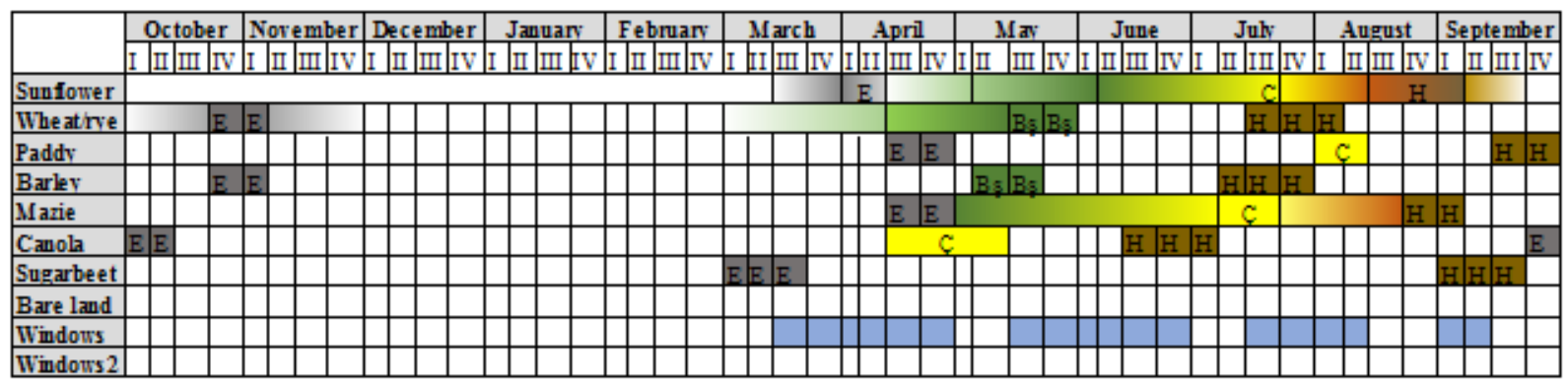

Figure 3. Crop phenology calendar matrix and windows of satellite image time series.

E: Sowing, Bs: Earing, Ç: Flowering, H: Harvest

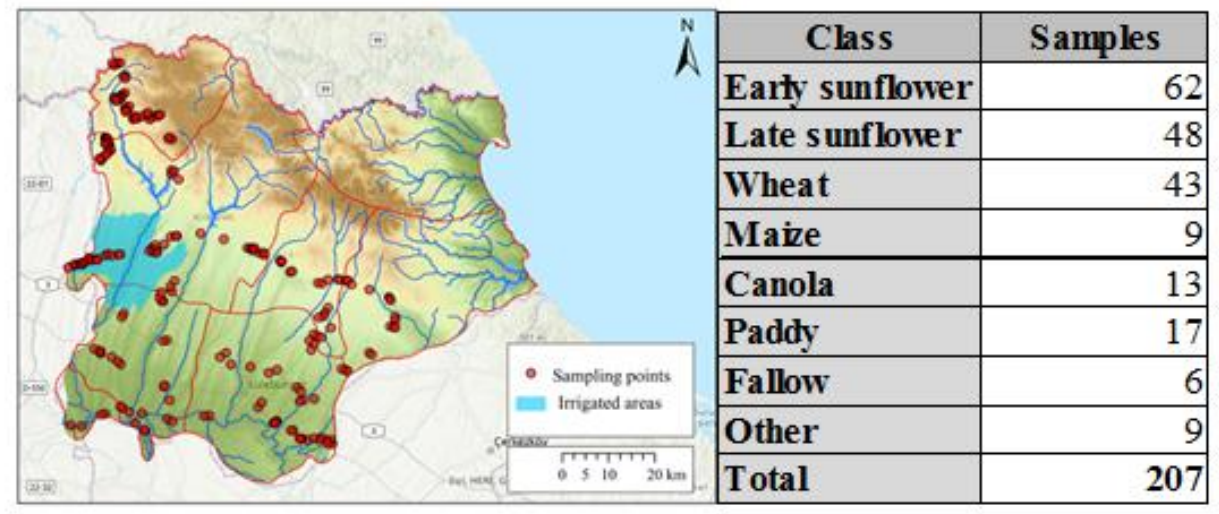

Figure 4. Main crops and sampling data set.

However, sunflower can also be planted as a second crop in addition to silage maize, especially in the areas damaged by unexpected adverse (e.g. frost, drought, flood) climate conditions. A time window series of 18 weeks was determined on the phenology calendar matrix in order to set the SENTINEL-2A image series that can be used for crop classification (Figure 3). Developing classification algorithms according to the spatiotemporal distribution structures of all these data creates an ordered and complex structure.

Figure 3 shows growth periods of the main crops grown between March and October. Colouring of cells is determined according to the growth cycle processes of the crops. Accordingly, the sowing (transition from white to green colour), vegetation (green colour), flowering (yellow colour), ripening (orange colour) and harvesting periods (transition from dark orange to white colour) were indicated with appropriate colours. In order to represent the phenological phases at different times and to describe them in multi-time images, a weekly time scale was created by dividing each month into four equal periods (Figure 3). Crop phenology was considered as a key factor in order to distinguish the crops (Waldhoff et al., 2017; Oetter et al, 2000; PaxLenney and Woodcock, 1997). Crop classification strategy was determined considering the phenological growth period of the crops (Table 1). Summer and winter crops can be effectively distinguished in the April images thanks to the contrast between these two seasonal groups on the images.

\section{Auxiliary GIS layers}

In order to minimize confusion (error rate) that may occur between the classes and other land uses in the classification processes, agricultural lands were masked using the CORINE CLC 2018 layer, and controlled with pasture and forest layers (Table 2).

In this way, classification was performed only in the agricultural areas. The river network, irrigated areas determined by State Hydraulic Works (DSI), lakes, ponds and roads sub-layers (Table 2) were prepared for class extraction processes which is performed by proximity or object-shape analysis in algorithms when necessary. These data layers were also used to identify suitable representative sample parcels for field work. 
Table 1. Multispectral image windows timeframe and crop classification strategy by crop phenology for Kırklareli.

\begin{tabular}{lll}
\hline Window & $\begin{array}{l}\text { Approximate } \\
\text { time period }\end{array}$ & Main classification goals \\
\hline 1 & $\begin{array}{l}\text { 1 March- 30 } \\
\text { April }\end{array}$ & $\begin{array}{l}\text { Bare land, winter cereals, } \\
\text { winter rape (canola), } \\
\text { summer crops }\end{array}$ \\
\hline 2 & 15 May-30 June & $\begin{array}{l}\text { Rapeseed, sunflower, } \\
\text { sugar beet, maize }\end{array}$ \\
\hline 3 & $15 \quad$ July-15 & $\begin{array}{l}\text { Wheat,sunflower, maize, } \\
\text { rapeseed, sugar beet }\end{array}$ \\
\hline 4 & $14 \quad$ August-15 & $\begin{array}{l}\text { Paddy, sugar beet, maize } \\
\text { sunflower }\end{array}$ \\
\hline 5 & September & Sugar beet \\
\hline
\end{tabular}

Table 2. Auxiliary GIS layers.

\begin{tabular}{|c|c|c|}
\hline $\begin{array}{l}\text { Auxiliary GIS } \\
\text { layers }\end{array}$ & Resolution & Source \\
\hline 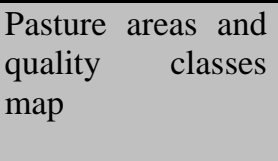 & Polygon & $\begin{array}{l}\text { (Avağ et al., 2012), } \\
\text { National Pasture Use } \\
\text { and Management } \\
\text { Project }\end{array}$ \\
\hline $\begin{array}{l}\text { Topography } \\
\text { (elevation, slope, } \\
\text { aspect) }\end{array}$ & $30 \mathrm{~m}$ & SRTM \\
\hline $\begin{array}{l}\text { Administrative } \\
\text { city and district } \\
\text { borders }\end{array}$ & Polygon & TARM-GIS database \\
\hline $\begin{array}{l}\text { Corine Land Use } \\
\text { (CLC) 2018, }\end{array}$ & $100 \mathrm{~m}$ & (EEA, 2018) \\
\hline Roads map & Polygon & KGM \\
\hline $\begin{array}{l}\text { River network } \\
\text { map }\end{array}$ & Polygon & TARM-GIS database \\
\hline Irrigated Areas & Polygon & DSI \\
\hline Satellite images & $10 \mathrm{~m}$ & $\begin{array}{l}\text { ESA-The Copernicus } \\
\text { Sentinel-2A }\end{array}$ \\
\hline $\begin{array}{l}\text { Forest areas } \\
\text { (MESCERE) }\end{array}$ & Polygon & TOB \\
\hline
\end{tabular}

Stepwise segmentation algorithms were developed based on the literature to produce an "agricultural parcel layer" that would be used in classification algorithms. Segmentation (object-parcel) results were compared with the control parcels that were downloaded from the General Directorate of Land Registry and Cadastre Parcel Inquiry Portal (APIS, 2020).

\section{Sampling dataset and NDVI time series for main crops}

Two different sampling data sets were created for learning and validation (test) processes with the sampling parcels that are collected with GPS in the field work (At least $50 \%$ of sampling parcels were used in validation for each class) (Figure 4). Better classification results can be expected with the higher number of learning samples that are distributed homogenously in the area, and if they are taken from at least 10 different parcels for each crop. (Waldhoff et al., 2017; Zhong et al., 2016; Islam et al., 2016; Panchal et al., 2021; Mehda et al., 2021).

\section{Monthly NDVI Time Series (2018)}

Normalized vegetation difference index (NDVI) is widely used in classification of land use, vegetation cover and crops (Ünal et al., 2004; Tucker et al., 2005; Wardlow and Egbert, 2008; Y1ld1z et al., 2012; Zheng et al., 2015; Skakun et al., 2017; Li et al, 2019). Within the scope of the study, NDVI time series of available clear images that represent the plant phenological periods were produced (Figure 5). The NDVI time series can effectively reveal the growth periods of the crops (Tucker et al., 2005; Zheng et al., 2015; Zhong et al., 2016; Skakun et al., 2017). The NDVI values and differences in the growth periods of main crops were determined and used as criteria in both segmentation and classification algorithms (Figure 5). NDVI time series for georeferenced learning and test (validation) sample parcels were produced for each crop depending on the average and median NDVI values of each parcel. Finally, the phenological growth cycle graphs of the main crops were produced as shown in Figure 5. VI (NDVI) values representing beginning of vegetation (D1), highest (D3) and ending (D4) periods of crop growth were determined by use of a limited number (7) of appropriate images for the stepwise separation of winter and summer crops (Figure 5) (Zhong et al. , 2016).

\section{Development of decision tree rules \& algorithms for segmentation and classification}

Tree-based learning algorithms are the most commonly used supervised learning algorithms in classification techniques, and can generally be adapted to solution of problems (classification and regression) that were addressed in almost every discipline (Friedl and Brodley, 1997; Yang et al., 2003; Çalış et al., 2014). The decision tree rule series of the study consists of two stages: The first stage includes creation of the objects (approximateparcels), namely stepwise segmentation algorithm processes, and the second stage includes stepwise classification algorithm processes (Figure 6).

The agricultural parcels are essential data layer in the studies of crop pattern determination and crop yield monitoring. If this layer does not exist, the most basic step is to create a layer of approximate-parcels using the most appropriate segmentation processes by determining crop field boundaries. In our study, The "Canny edge detection" algorithm, one of the methods proposed by Watkins and van Niekerk (2019) for automatic determination of agricultural parcel, was applied using time series of different bands and NDVI layers. Later, a series of different segmentation algorithms (Multispectral-Spectral difference-Region grow) were performed to achieve the best result. Since there was no digital parcel layer, the results were compared visually with the satellite images of different periods, and appropriate parcellation was produced (Alganci et al., 2013).

A classification decision tree consisting of rule series was created based on the method of "covering-bottom up-separate-conquer" depending on the crop phenological stages (Zhong, et al., 2016; Waldhoff et al., 
2017; Zhong and Zhou, 2019). In this method, all samples in the rules are parsed, and remaining ones are transferred to a class. Stepwise process continues until all classes are assigned (Zhong et al., 2019). The differences of NDVI values in the crop growth cycle like growing (high vegetation index), maturity and harvest (low vegetation index) periods effectively worked in the crop separation processes. The NDVI, RGB and NIR reflectance values in the phenological periods and physical parameters (length / width ratio etc.) were used as separation criteria in the classification algorithms.

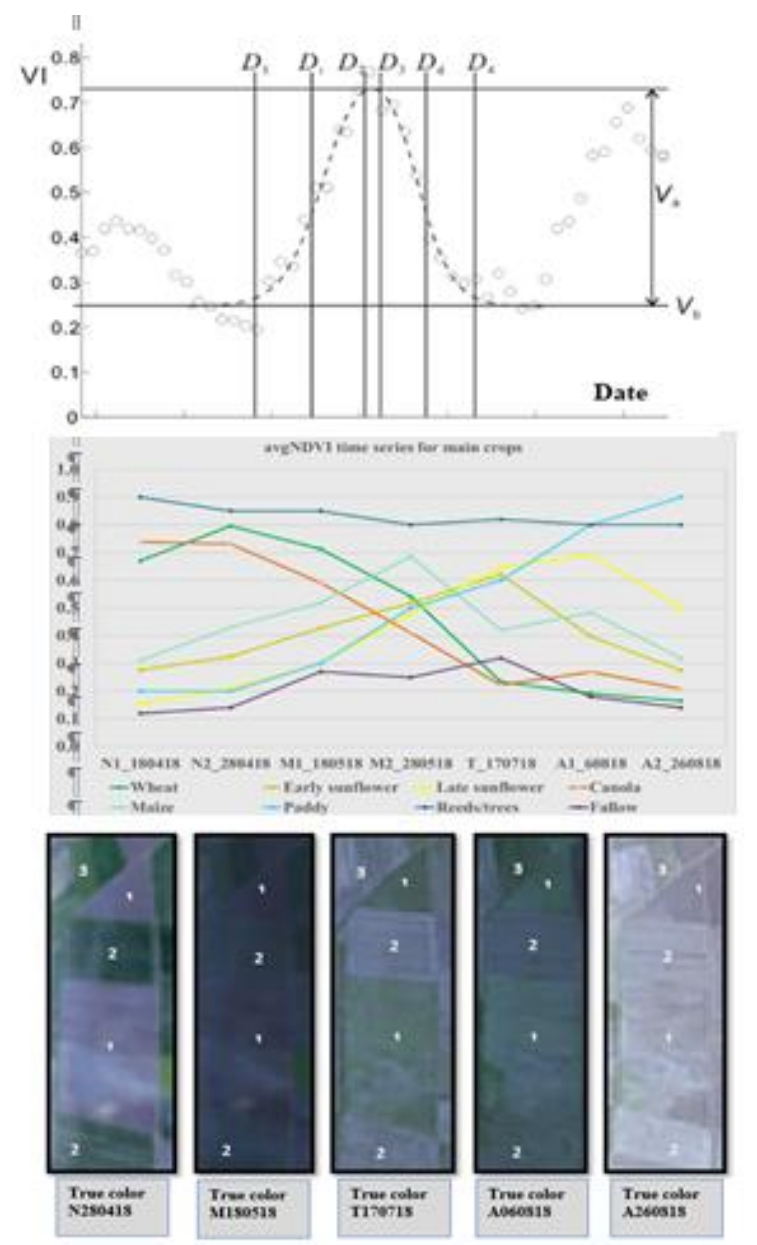

Figure 5. NDVI Time series (Di) and decision threshold (Vj) values of crops (after Zhong, et al., 2016).

The growth cycle of some crops could not be fully captured due to absence of clear images in March, June and September. However, more precise classification results can be obtained by knowing exact sowing date of the crops, and using a day of the year criterion for the crop growth cycle effectively in the algorithms (Zhong et al., 2016).

Classes were determined only for the main crops in the study area. Sugar beet, alfalfa, legumes and other crops were grouped under the "other" class since the study focused on the determination of sunflower fields.

\section{Confusion matrix and accuracy assessments}

The sampling parcels, which were qualified to represent the main crops and determined in homogeneous distribution as far as field conditions allow, were used in identifying the criteria in the classification processes. Half of the samples (50\%) was used as test (validation) data set in confusion matrix and accuracy analysis. The confusion matrix was created using the test data set to compare estimated classified parcels with actual classes that were determined in the field.

Classification performance was validated by confusion matrices, accuracy parameters (User's Accuracy (UA) and Producer's Accuracy (PA), the Overall Accuracy (OA) and Kappa Coefficient (K)), and confusion error (Congalton and Green, 2009; Zhong et al., 2016; Waldhoff et al., 2017).

The Kappa coefficient, which shows accordance between actual crop parcels and overall classification results of the model, varies between $0-1$, and shows that the accuracy rate of the classification increases as it approaches 1 .

\section{Results}

\section{Segmentation and parceling}

As a first stage, "edge detection" algorithm (automatic determination of parcel boundaries) was applied for each band layer (e.g. April NIR, July R band etc.) and NDVI time series. We selected layers that provide the best contrast in the cultivated areas using the time series of the year 2018 which consists of seven different time periods. The images of May did not provide high contrast in the parcel boundaries, since nearly each crop was in a period of high vegetation growth. On the other hand, as each image band and NDVI layer had different levels of contrast in different parcels, we overlayed all these layers to obtain the final explicit parcel boundaries layer (Figure 7).

As a second stage, segmentation was performed by iterating different combinations of weight coefficients for each band layer as well as the final parcel boundaries layer. The best segmentation result was obtained when the highest weight coefficient is given to the 'Canny Edge' layer ( Figure 7).

The "Multispectral segmentation" method was applied as the first step in the segmentation process (8a,b,c and d). In this method, different weight coefficients were given to each image band layer and combinations of different segmentation parameters were tried. As "scale" value, which is one of the determining parameters of this method, increases, size of the object also increases. High values of "shape" parameter disrupted the homogeneous structure of RGB-NIR and NDVI values in the object. It was observed that high "compactness" values also enable to obtain a more detailed parcel structure that increases the number of the objects. Considering these effects, many different parametric combinations were iterated to achieve the best final parcels layer.

The results of the segmentations were compared on the images and the most appropriate segmentation result was accepted as a final parcels layer for use in the 
classification processes. (Figure $8 \mathrm{c}$ and d). However, more effective segmentation result can be obtained by developing additional auxiliary algorithms by using

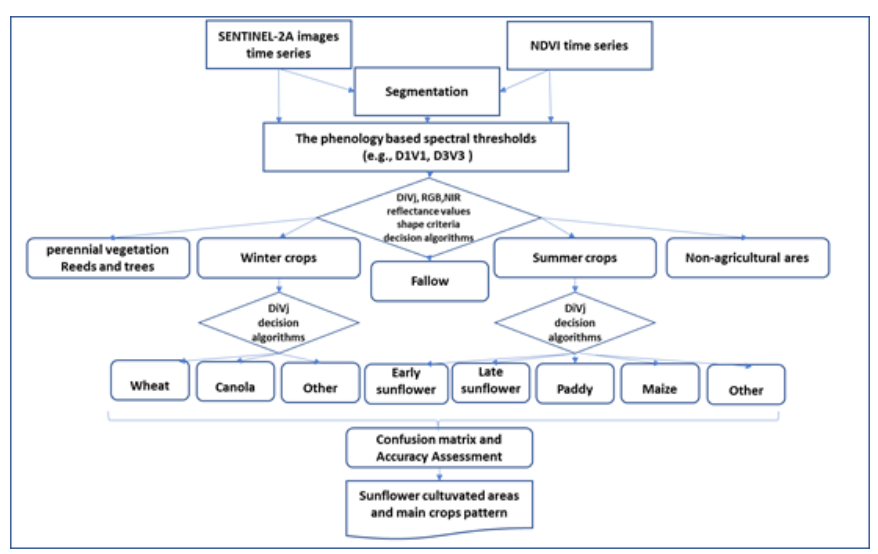

Figure 6. Flowchart of segmentation and classification decision tree rules

As a result of "Multispectral segmentation" 66.075.107 objects were determined. Some neighbouring objects with similar features was combined to reduce the vast number of objects that were straining the processing capacity of the hardware and software. For this purpose, "Spectral difference segmentation" and "region grow" methods were applied as the second step. At this stage, similar segments were combined using the mean differences of NDVI and band layers, and giving different weight coefficients to each layer. As a result, the number of objects has been reduced to 201.221. Actual cultivated areas and segmentation parceling results were visually compared on the satellite images for different periods, and made ready for classification process (Figure 8d). The parceling differences in the stepwise segmentation processes and their compatibility with the images can be clearly observed from the parcels in the red circle. (Figures 8a-d).

Desired comparison result could not be achieved since the land registry cadastral parcels and actual cultivated parcels were not very compatible (Figure 9). For this reason, the final parcels layer was decided by comparing the segmentation parcels with the actual cultivated areas on the satellite images at different phenological periods. (Figure 8d). In Turkey, agricultural parcels can be very small in size, and parcel size is varying between 5-20 ha in Kirklareli. Small-sized agricultural parcels can cause a vast number of objects depending on the algorithm criteria; therefore, automatically identifying parcels through segmentation processes can strain the processing capacity of the computer. Another bottleneck during the segmentation processes is in-field differences that is observed in a same parcel which can be resulted from the spatial variability of land and crop vegetation or differences in available digital agricultural parcel data, and the segmentation results can be compared more precisely by calculating error rates.
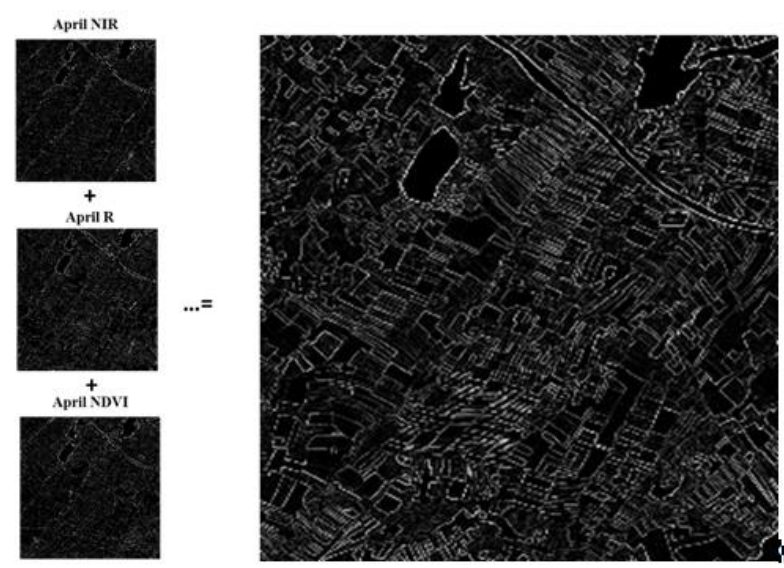

Figure 7. Agricultural parcel boundaries layer (Canny edge layer). In the image bands and NDVI time series, the "Canny edge" boundary layers with high contrast were determined and combined as final raster. Non-agricultural areas are masked using auxiliary GIS layers.

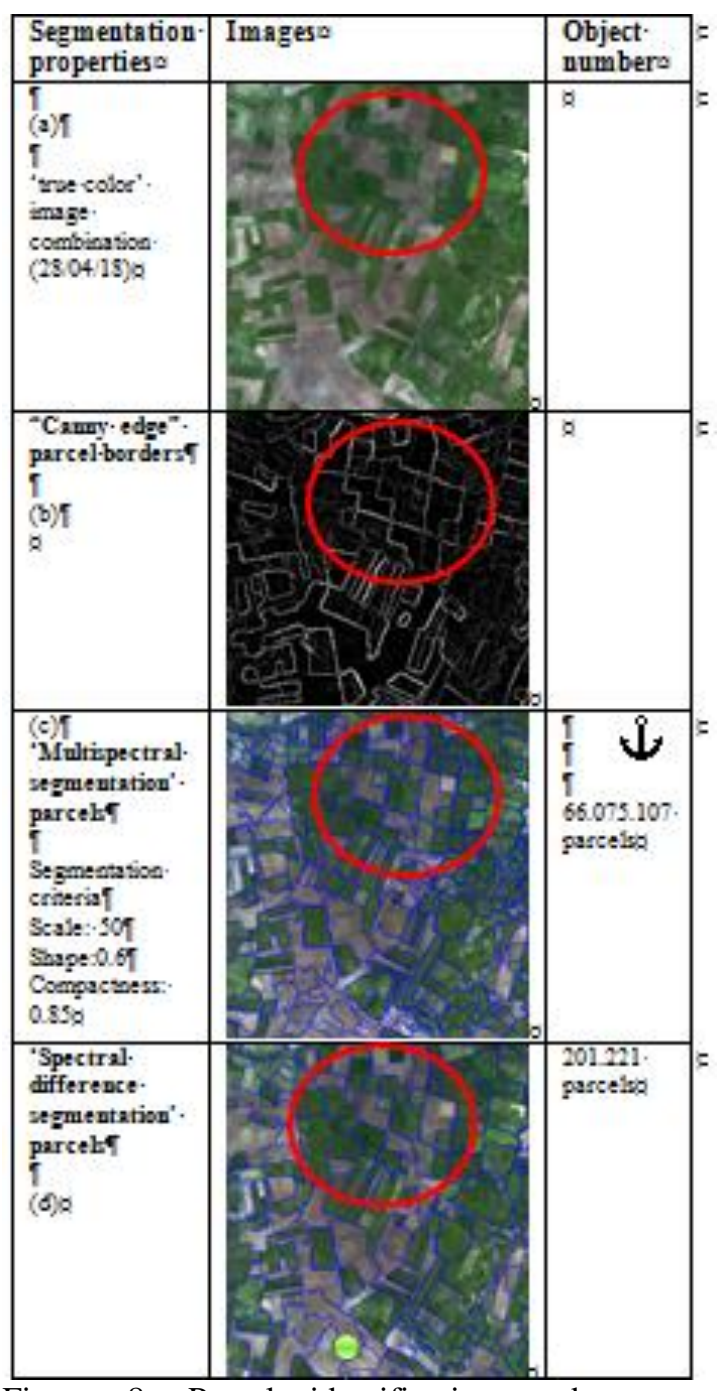

Figure 8. Parcel identification and segmentation processes. 
simultaneous-time image frames. The "region grow" and "spectral difference segmentation" methods were effectively performed overcoming these problems by merging in-field parts (Figure 8d).

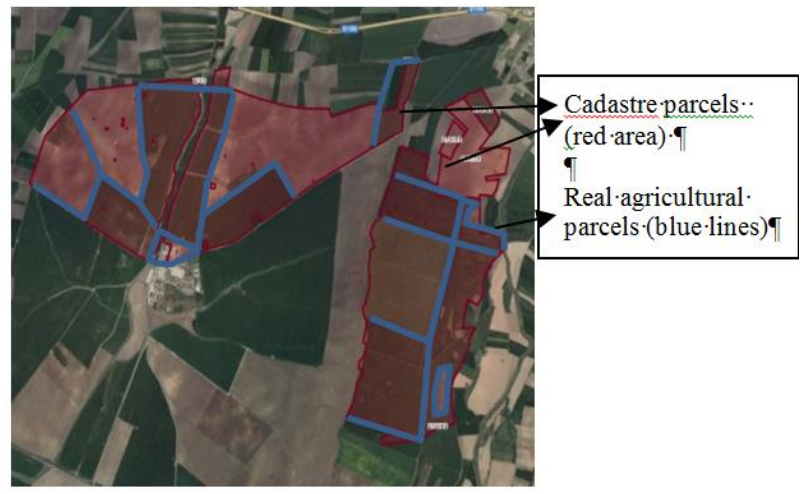

Figure 9. Cadastre (red polygons) parcels and segmentation parcels (blue polygons).

\section{Sunflower cultivated areas and main crops pattern}

The final parcels layer was used as a basement object layer for the classification processes. The classification decision tree and rule set were created using the NDVI and RGB time series of each crop. In addition to that, the shape criteria were also used in the classification algorithms where it is necessary. Firstly, permanent green (woodland between the fields and reeds) and bare lands (fallow, crossroad, etc.); then winter and summer crops were determined. In the second stage, summer and winter crops were again separated by crop-based classification algorithms using periodic differences in the NDVI and reflectance values of the layers. Finally, the crops that could not be distinguished and the rest of the "unclassified" segments were grouped under the "other" class (Figure 10). The maximum, minimum, average and median values of the NDVI were iterated at different threshold levels for each crop in the classification algorithms. The crops pattern map was produced using the iteration result with the lowest standard error and highest classification goodness coefficient (Kappa) of confusion matrix (Figure 10).

As a result, sunflower cultivated areas were precisely determined by developing site-specific object-oriented classification algorithms (Figure 10). According to our classification result, the estimated sunflower cultivated areas were 89,487 ha in total for the year 2018, and the result was compared with TÜİK (TÜİK, 2018) and ÇKS (ÇKS-TOBB, 2018) data sources. Sunflower cultivated areas that we estimated are 14400 and 19500 ha higher than those of TÜIKK and ÇKS data, respectively. Furthermore, approximately 8000 ha of differences was observed between both data sources. In conclusion, in our study, early and late sunflowers were classified with $98 \%$ and $92 \%$ accuracy, respectively, with the sampling parcels. These differences in data sources of different institutions once again reveals a need of establishing a centralised systematic control mechanism that is supported by remote sensing technologies, keeping up with the ever-evolving technology in the field.

\section{Confusion matrix and accuracy assessments}

The appropriate number of samples that are homogeneously distributed over the whole study area (at least 10 samples per crop parcel) is an important factor to increase the accuracy of the classification (Foody, 2005; Zhong et al., 2016; Waldhoff et al., 2017; Khaliq et al. al., 2018). However, the actual terrain and weather conditions often do not let researchers perform the same grid sampling pattern that is prepared at the desk, and require us to adapt to the real-time conditions in the field (see Figure 4).

Confusion matrix and accuracy coefficients (P_accuracy, U-accuracy, Kappa) are indicators that indicate performance of classification (Congalton and Green, 2009; Zhong and Zhou, 2019). These indicators provide us to control how accurately classification criteria values obtained with actual ground data.

The learning sampling dataset was used when creating the criteria at the classification processes while the test sampling dataset was used in setting the Confusion matrix to determine accuracy of the classification (Figure 11).

While 4 out of 70 test samples of early sunflower were confused with late sunflower, 3 of samples was confused with the "other" class (Figure 11). Likewise, confusion occurred between the late sunflower and paddy classes. The lowest accuracy percentage $(0.22)$ was obtained in the "other" class due to the insufficient learning and test samples. Likewise, insufficient accuracy rate was obtained in the maize (0.67) and paddy (0.76) classification due to the small number of sampling as well. This confusion between paddy and second or late sunflower is thought to be the result of a coincidence of their growth periods when they reach the highest vegetation levels. For this reason, it would be appropriate to develop intermediate algorithms by using different properties (distinctive reflectance differences in different periods and bands) to eliminate this confusions.

The differences in the reflectance and NDVI values of sunflower during the sowing, ripening and harvesting periods allowed to create very good class assignment algorithms despite the confusions that encountered in the classification. Finally, early and late sunflowers were classified with $98 \%$ and $92 \%$ accuracy, respectively. Although sunflower itself provided high accuracy, the lack of sufficient representative samples for other crops reduced the overall accuracy of the classification (Kappa: 0.82). Increasing the number of samples for all crops makes it possible to obtain more precise results as it can improve the crop separation algorithms. 


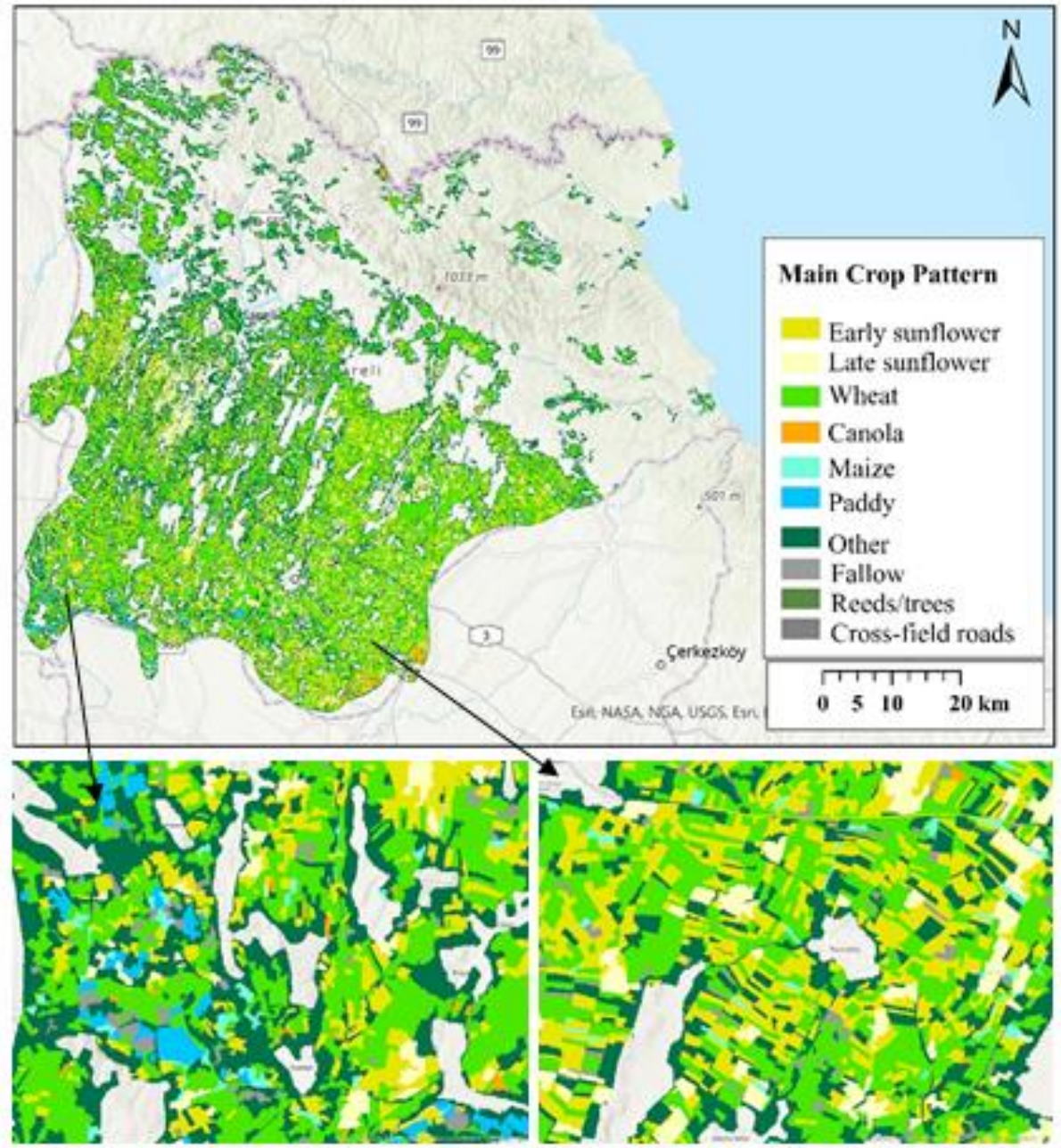

Figure 10. Sunflower cultivated areas and main crop pattern in Kirklareli (2018).

\begin{tabular}{|c|c|c|c|c|c|c|c|c|c|c|c|}
\hline Class & Early sumflower & Late sunflower & Whe at & Maive & Canola & Paddy & Fallow & Other & Total & U_Ascuracy & Kappa \\
\hline Earky sumflower & 61 & \begin{tabular}{r|}
1 \\
\end{tabular} & \begin{tabular}{|l|}
0 \\
\end{tabular} & 0 & \begin{tabular}{|l|}
0 \\
\end{tabular} & \begin{tabular}{r|}
0 \\
\end{tabular} & 0 & of & 62 & \begin{tabular}{|r|}
0.98 \\
\end{tabular} & 0 \\
\hline Late sunflower & 4 & 44 & 0 & 0 & 0 & 0 & 0 & 0 & 48 & 0.92 & 0 \\
\hline Whe at & 0 & 0 & 36 & 0 & 6 & 0 & 0 & 1 & 43 & 0.84 & 0 \\
\hline Maive & 1 & 요 & 1 & 6 & of & 0 & 0 & 1 & 9 & 0.67 & 0 \\
\hline Canola & 0 & 0 & 2 & 0 & 11 & 0 & 0 & 0 & 13 & 0.85 & 0 \\
\hline Paddy & 0 & 4 & 0 & 0 & 0 & 13 & 0 & 의 & 17 & 0.76 & 0 \\
\hline Fallow & 1 & 요 & 0 & 0 & 의 & 0 & 5 & 0 & 6 & 0.83 & 0 \\
\hline Other & 3 & 1 & 1 & 1 & 0 & 1 & 0 & 2 & 9 & 0.22 & 0 \\
\hline Total & 70 & 50 & 40 & 7 & 17 & 14 & 5 & 4 & 207 & of & 의 \\
\hline P.Accuracy & 0.87 & 0.88 & 0.9 & 0.86 & 0.65 & 0.93 & 1 & 0.5 & 0 & 0.86 & 0 \\
\hline Kappa & 0 & ol & o] & ol & ol & ol & 0 & 이 & 0 & ol & 0.82 \\
\hline
\end{tabular}

Figure 11. Confusion matrix and accuracy coefficients.

\section{Discussion}

Our primary aim in this study was to develop a methodology for determining sunflower cultivated areas using crop growth cycle time series of satellite images and vegetation index (NDVI). For this purpose, a pilot study was conducted to determine one-year (2018) crops pattern for the province of Kirklareli. Sampling study was carried out to set crop-based learning and test datasets in July. However, in order to make long-term crop production planning, a spatio-temporal database of crop rotation pattern is essential (Waldhoff et al., 2017).

In this study, classification decision algorithms were developed by overlapping the sampling parcels with spectral signature and NDVI time series. The algorithms were developed by creating sub-regions in different land structures in the East-West-North-South directions of the study area, and tested in the whole area in order to achieve the final decision.

A parceling structure that could represent the actual cultivated areas was produced in order to make objectoriented crop classification with image processing techniques. A series of segmentation algorithms was developed in the creation of this parceling structure (Watkins and Van Niekerk, 2019). The biggest problem encountered in segmentation was the identification of non-agricultural areas. Especially, determining the roads between the fields and scattered settlements required a 
different sorting process. In order to reduce the impact of non-agricultural areas on the classification quality, the agricultural areas were masked using CORINE 2018 CLC and other auxiliary GIS layers. Better results were obtained when segmentation and subsequent classifications were performed on this masked layer. However, despite the masking, scattered settlements, woodlands, reeds, transitions between the fields in the agricultural areas caused irregularities in segmentation. Some auxiliary thematic layers such as roads, river network etc. were used to create a proximity and shape algorithms to reduce the confusion and oversegmentation that was resulted from these irregular structures (Waldhoff et al. (2017; Zhong, et al., 2016; Zhong and Zhou, 2019). However, some of these thematic layers (e.g. river network) did not fit the actual terrain when overlapped with satellite images due to the errors in coordinate transformations and/or digitization. For this reason, highly incompatible layers were not included in the classification decision algorithms.

The test sample parcels were downloaded from the cadastral parcels data portal of the General Directorate of Land Registry and Cadastre, and the segmentation parcels were compared with the cadastral parcels. However, the existence of different crop areas and different agricultural practices in a single cadastral parcel made this comparison meaningless. (Figure 9). As a matter of fact, since the algorithms were created over the actual status of the cultivated areas using the satellite images, the segmentation parcels were directly compared with the satellite images, and the iteration process continued until the most visually optimal result was obtained.

Crop-based classification decision algorithms were developed using the crop growth threshold values of spectral signature and NDVI time series. These algorithms were tested with different periodic threshold values and classification hierarchies, and then improved with the confusion matrix and error coefficients (Congalton and Green, 2009; Zhong and Zhou, 2019).

As a result, a high accuracy level of $98 \%$ has been obtained in determining the early sunflower cultivated areas while improvement is still required in determining the late sunflower $(92 \%)$ areas as well as the other main crops.

\section{Conclusion}

Crop growth periods may differ in terms of both crop growth cycle and remotely sensed features depending on many factors such as climate, topography, altitude, soil characteristics, variety and irrigation. For this reason, the crop pattern should be evaluated depending on these change factors, and the classification algorithms should be developed on a local basis by creating subhomogeneous areas. In Turkey, crop monitoring is performed according to the farmer's statements that are registered in the farmer registration system (ÇKS). Although the accuracy of these statements is discussed on every platform, still no technological monitoring system has been established across the country or regionally. Within the scope of the Agricultural Information System (TARBIL), an agricultural observation network was established with considerable investments. A vast amount of data was accumulated through this monitoring network, but unfortunately, it could not be transformed into a valuable information for decision-makers due to its underlying complexity.

Turkey has very variable topographical, morphological, soil and climate characteristics. This complex structure makes it almost impossible to manage crop monitoring in a national scale with a holistic approach. Even though the agricultural basins were produced to serve regional action plans, they are still insufficient since spatiotemporal changes of cultivated areas are not being monitored by real-time remote sensing data. This study shows that a local algorithm approach is needed even in an area of $6550 \mathrm{~km}^{2}$ (Kirklareli) where the difference in altitude is about $200 \mathrm{~m}$. Therefore, better economic solutions for crop monitoring actions in Turkey can be planned in local and regional scale using time series of high resolution low-cost or free images like SENTINEL $2 \mathrm{~A}$.

Mapping of crop rotation and yield estimates are an increasing requirement to determine effective governmental subsidies for crop production, and to develop policies that can be measured more accurately in production planning. Considering the size of Turkey's agricultural lands and the current agricultural potential, we are still increasingly dependent on imports for many agricultural products. However, we can overcome this struggle with domestic agricultural production by developing innovative and applicable low-cost local crop production monitoring systems, and with effective farmer/producer support policies based on controllable spatio-temporal data. Therefore, it is an inevitable fact that central and local governments should cooperate in order to develop local crop monitoring and management systems and to provide more effective support to farmers/producers. The crop pattern variety can be detailed by increasing the learning and test samples of all cultivated crops especially the crops in the 'other' class in future works of this area. All grains were grouped in the 'wheat' class due to the high amount of wheat cultivation than other cereals. However, in the future studies, methods can be developed for separation of similar crops such as cereals by increasing the radiometric and spatial resolutions besides more detailed crop-based field observations.

In this study, with its methodological approach, has revealed that crop pattern can be accurately determined by using time series of high spatial-radiometric resolution satellite images and including field observation into the classification algorithms that is performed by crop experts.

\section{Acknowledgements}

This study was performed within the scope of the "National Product Monitoring and Yield Estimation 
Project" that was supported by TOB-TAGEM Research Program.

\section{References}

Alganci, U., Ozdogan, M., Sertel, E., Ormeci, C. (2014). Estimating maize and cotton yield in southeastern Turkey with integrated use of satellite images, meteorological data and digital photographs. Field Crops Research, 157, pp.8-19.

Alganci, U., Sertel, E., Ozdogan, M., Ormeci, C. (2013). Parcel-level identification of crop types using different classification algorithms and multiresolution imagery in southeastern turkey. Photogrammetric Engineering \& Remote Sensing, 79(11), 053-1065.

APIS (2020). Agricultural Parcels Information System

Bakanoğulları, F. (2018). Sensitivity Analysis of Sunflower and Wheat Crops to Climate Change using the AquaCrop Model, Research Project. TAGEM/TSKAD/14/A13/P01/05. Kirklareli Atatürk Soil, Water, and Agricultural Meteorology Research Institute.

Balcik, F. B. and Kuzucu, A.K. (2016). Determination of land cover/land use using spot 7 data with supervised classification methods. The International Archives of Photogrammetry, Remote Sensing and Spatial Information Sciences, 42, 143.

Bargiel, D. (2017). A new method for crop classification combining time series of radar images and crop phenology information. Remote sensing of environment, 198, 369-383.

Çaldağ, B. (2009). Determination of Agri-meteorological Characteristics of Thrace Region, PhD Thesis. Istanbul University, Institute of Sciences, İstanbul.

Çalış, A., Kayapınar, S., Çetinyokuş, T. (2014). An Application on Computer and Internet Security using Decision Tree Algorithms in Data Mining. Journal Of Industrial Engineering (Turkish Chamber Of Mechanical Engineers), 25.

Çiçek, G., Kurucu, Y.(2018). Determination of MultiBand Spectral Signatures of the Phenological Stages for Potato and Beet Plants in Central Anatolia VII. Remote Sensing Symposium, 2018, Eskişehir

Çölkesen, I., Kavzoglu, T. (2017). Ensemble-based canonical correlation forest (CCF) for land use and land cover classification using sentinel-2 and Landsat OLI imagery. Remote Sensing Letters, 8(11), 10821091.

Congalton, R.G. and Green, K. (2009). Assessing the Accuracy of Remotely Sensed Data: Principles and Practices. CRC Press, Boca Raton.

Corine Land Cover (2018). Corine-CLC (Online) Version 2020_20.

De Wit, A.J.W., Clevers, J.G.P.W. (2004). Efficiency and accuracy of per-field classification for operational crop mapping. Int. J. Remote Sens. 25, 4091-4112, doi.10.1080/01431160310001619580.

Drury, S.A. (1990). A guide to remote sensing: interpreting images of the earth.

Erginal, G., Uludağ, M. (2018). Natural and anthropogenic threats to the cultural tourism potential of Kıyıköy, Kırklareli, Turkey. International Journal of Environment and Geoinformatics, 5(3), 296-303, doi.10.30897/ijegeo.465547

Esetlili, M., Bektas Balcik, F., Balik Sanli, F., Kalkan, K., Ustuner, M., Goksel, C., Gazioğlu, C., Kurucu, Y. (2018). Comparison of Object and Pixel-Based Classifications For Mapping Crops Using Rapideye Imagery: A Case Study of Menemen Plain, Turkey. International Journal of Environment and Geoinformatics, 5(2), 231-243, doi.10.30897/ijegeo. 442002.

Esetlili, M.T., Kurucu, Y. (2003). A research on supervised classification methods in determining cotton plantations using remote sensing technique. Ege Üniversitesi Ziraat Fakültesi Dergisi, 40(2).

ESKGM- Ministry of Commerce (Ticaret Bakanlığı) (2019). Sunflower Report for the year 2018.

European Union-Copernicus (2019). EU-Copernicus

Evsahibioğlu, A.N. (1994). Wheat cultivation area and yield forecasts in Thrace region with remote sensing techniques. II. Seminar of Remote Sensing and Applications in Turkey II. Uzaktan Algllama ve Türkiye'deki Uygulamaları Semineri), Uludağ-Bursa.

Foody, G.M. (2005). Local characterization of thematic classification accuracy through spatially constrained confusion matrices. International Journal of Remote Sensing, 26(6), 1217-1228.

Friedl, M.A.A., Brodley, C.E. (1997). "Decision tree classification of land cover from remotely sensed data." Remote sensing of environment, 61(3), 399409.

FRS (2020) Farmer Registration System

GA U (2015) Transforming our world: the 2030 Agenda for Sustainable Development. Division for Sustainable Development Goals: New York, NY, USA.

Ghamisi, P., Plaza, J., Chen, Y., Li, J., Plaza, A.J. (2017). Advanced spectral classifiers for hyperspectral images: A review. IEEE Geoscience and Remote Sensing Magazine, 5(1), 8-32.

Göneci, E. (2019). Determination of Sunflower Cultivated Areas in Different Planting Regions by Remote Sensing Technique. PhD Thesis.

İrfanoğlu, F., Bektaş Balçık, F. (2018). "Determination of LULC Categories using Object Based Classification and Sentinel-2 MSI data." UZALCBS, Eskisehir, Turkiye (2018).

Islam K, Jashimuddin M, Nath B, Nath TK (2016) Quantitative Assessment of Land Cover Change Using Landsat Time Series Data: Case of Chunati Wildlife Sanctuary (CWS), Bangladesh. International Journal of Environment and Geoinformatics 3(2): 45-55.

Khaliq, A., Peroni, L., Chiaberge, M. (2018). Land cover and crop classification using multitemporal Sentinel2 images based on crops phenological cycle. IEEE Workshop on Environmental, Energy, and Structural Monitoring Systems (EESMS) (pp. 1-5). IEEE.

Kuru, A., Terzi, F. (2018). Determination of New Development Area in Kirklareli by GIS Based Weighted Overlay Analysis. International Journal of Environment and Geoinformatics, 5(3), 244-259, doi. 10.30897/ijegeo.427330. 
Li, C., Li, H., Li, J., Lei, Y., Li, C., Manevski, K., Shen, Y. (2019). Using NDVI percentiles to monitor realtime crop growth. Computers and Electronics in Agriculture, 162, pp.357-363.

Maxwell, A.E., Warner, T.A., Fang. F., (2018). Implementation of machine-learning classification in remote sensing: An applied review. International Journal of Remote Sensing, 39(9), 2784-2817.

Mehta, D., Shukla, S., Kalubarme, M. (2021). Winter Crop Growth Monitoring using Multi-Temporal NDVI Profiles in Kapadvanj Taluka, Gujarat State, International Journal of Environment and Geoinformatics, 8(1), 33-38, doi.10.30897/ ijegeo.773860.

MGM (2014). Turkey's Crop Fenology Atlas (O. Şimşek, Y. Nadaroğlu, G. Yücel, Ö. Dokuyucu, Ş. A. Gökdağ, M. Yıldırım, Türkiye Fenoloji Atlası, Araştırma Dairesi Başkanlığı, Zirai Meteoroloji Şube Müdürlüğü.

MGM-General Directorate of Meteorology. (2018), Climate Data Portal

Oetter, D.R., Cohen, W.B., Berterretche, M., Maiersperger, T.K., Kennedy, R.E., (2000). Land cover mapping in an agricultural setting using multiseasonal Thematic Mapper data. Remote Sens. Environ. 76, 139-155, doi.10.1016/S00344257(00)00202-9.

Panchal, J., Shukla, S., Kalubarme, M. (2021). Analysis of Optimum Growth Stages for Winter Crop Separability using Multi-Temporal NDVI Profiles in Vijapur Taluka, Gujarat State. International Journal of Environment and Geoinformatics, 8(2), 135-143, doi.10.30897/ijegeo.803303.

Pax-Lenney, M., Woodcock, C.E. (1997). Monitoring agricultural lands in Egypt with multitemporal landsat TM imagery: how many images are needed? Remote Sens. Environ. 59, 522-529. doi.10. 1016/S0034-4257(96)00124-1.

Rahman, M.R. and Saha, S..K (2008). Multi-resolution segmentation for object-based classification and accuracy assessment of land use/land cover classification using remotely sensed data. Journal of the Indian Society of Remote Sensing, 36(2), 189201.

Sabins, Jr. F.F. (1987). Remote sensing--principles and interpretation. WH Freeman and company.

Skakun. S., Franch, B., Vermote, E., Roger, J.C., Becker-Reshef, I., Justice, C., Kussul, N. (2017). Early season large-area winter crop mapping using MODIS NDVI data, growing degree days information and a Gaussian mixture model. Remote Sensing of Environment, 195, 244-258.

TOB-(Ministry of Agriculture and Forestry), (2018). Agriculture Report of Kırklareli (Kırklareli Tarım Raporu)

TOBB-Mercantile Exchange of Kırklareli. (2018) Action Report for the year 2018.

Tucker, C.J., Pinzon, J.E., Brown, M.E., Slayback, D.A., Pak, E.W., Mahoney, R., Vermote, E.F., El Saleous, N. (2005). An extended AVHRR 8km NDVI dataset compatible with MODIS and SPOT vegetation NDVI data. International Journal of Remote Sensing, 26(20), 4485-4498.
TÜİK (2018). Crop Production Statistics

Turker, M., Arikan, M. (2005). Sequential masking classification of multi-temporal Landsat7 ETM+ images for field based crop mapping in Karacabey, Turkey. Int. J. Remote Sens. 26, 3813-3830. doi.10.1080/01431160500166391.

Unal, E., Mermer, A., Dogan, H.M. (2004). Determining major orchard (pistachio, olive, vineyard) areas in Gaziantep Province using remote sensing techniques. International Archives of the Photogrammetry, Remote Sensing and Spatial Information Sciences, 34.

Waldhoff, G., Lussem, U., Bareth, G. (2017). Multi-Data Approach for remote sensing-based regional crop rotation mapping: a case study for the Rur catchment, Germany. International journal of applied earth observation and geoinformation, 61, 55-69.

Wardlow, B.D., Egbert, S.L. (2008). Large-area crop mapping using time-series MODIS $250 \mathrm{~m}$ NDVI data: An assessment for the US Central Great Plains. Remote sensing of environment, 112(3), 1096-1116.

Watkins, B., Van Niekerk, A. (2019). Automating field boundary delineation with multi-temporal Sentinel-2 imagery. Computers and Electronics in Agriculture, 167, 105078.

Yang, C.C., Prasher, S.O., Enright, P., Madramootoo, C., Burgess, M., Goel, P.K. and Callum, I. (2003). Application of decision tree technology for image classification using remote sensing data. Agricultural Systems, 76(3), 1101-1117.

Yıldız, H., Mermer, A., Ünal, E. and Akbaş. F. (2012), Spatial and Temporal Analysis of NDVI data of Turkey's Vegetation Cover (Türkiye bitki örtüsünün NDVI verileri ile zamansal ve mekansal analizi). Tarla Bitkileri Merkez Araştırma Enstitüsü Dergisi, 21(2), 50-56.

Zheng, B., Myint, S.W., Thenkabail, P.S., Aggarwal, R.M. (2015). A support vector machine to identify irrigated crop types using time-series Landsat NDVI data. International Journal of Applied Earth Observation and Geoinformation, 34, 103-112.

Zhong, L., Hu, L., Yu, L., Gong, P., Biging, G.S. (2016). Automated mapping of soybean and corn using phenology. ISPRS Journal of Photogrammetry and Remote Sensing, 119, 151-164.

Zhong, L., Hu, L., Zhou, H. (2019). Deep learning based multi-temporal crop classification. Remote sensing of environment, 221, 430-443. 